\title{
Comparative Study of Urine Albumin Creatinine Ratio v/s Intima Media Thickening as a Marker of Atherogenicity in Ischaemic Heart Diseases
}

\author{
Talib S. H. ${ }^{1}$, Patil Sumit. ${ }^{2}$, Dase R. K. ${ }^{3}$, Pagar Bhushan ${ }^{4}$, Kanjani Indira ${ }^{5}$, Kurhade Aniket ${ }^{6}$ \\ ${ }^{1}$ Prof. \& H.O.D, Dept. of Medicine, MGM medical college, Aurangabad \\ ${ }^{2}$ Chief resident, Dept. of Medicine, MGM medical college, Aurangabad \\ ${ }^{3}$ Asso. Prof., Dept. of Community Medicine, MGM medical college, Aurangabad \\ ${ }^{4}$ Chief resident, Dept. of Medicine, MGM medical college, Aurangabad \\ ${ }^{5}$ Junior resident, Dept. of Medicine, MGM medical college, Aurangabad \\ ${ }^{6}$ Chief resident, Dept. of Medicine, MGM medical college, Aurangabad
}

\begin{abstract}
This study was done to detect better marker of atheroginicity among urine albumin creatinine ratio \& carotid intima media thickening in ischaemic heart disease. Albumin creatinine ratio outcome has more correlation with comorbidities that exist with ischaemic heart disease like diabetes mellitus\& hypertension which themselves can cause albumin excretion by causing nephropathy. Intima media thickness has direct association more with the progress of atherogenesis when comorbidities exist.
\end{abstract}

Keywords: Albumin creatinine ratio, Intima media thickness, Ischaemic heart disease, atheroginicity

\section{Introduction}

Atherosclerosis is the main cause of myocardial infarction that is causing more \& more deaths over the period. This study intends to detect if there is any relationship that exists between two different markers of atherogenicity viz.

1) Carotid intima media thickness (IMT)

2) Urine microalbumin : creatinine ratio (ACR)

Ischaemic heart disease is the most common cause of death in the world ${ }^{1}$. In India, ischaemic heart disease has become a leading cause of death, by 2004 accounting to 1.46 million deaths \& is expected to double by $2015^{2}$. Limitation of blood flow to the heart causes ischaemia (cell starvation secondary to a lack of oxygen) of the myocardial cells. Myocardial cells may die from lack of oxygen and this leads to ischaemic heart disease. There are certain predisposing factors like hypercholesterolemia, smoking, alcoholism, hypertension etc. Ischaemic heart disease may present as stable angina, unstable angina, acute coronary syndrome, myocardial infarction etc. ${ }^{3}$

Microalbuminuria i.e albumin: creatinine ratio(albumin creatinine ratio 30 to $300 \mathrm{mg} / \mathrm{lit}$ ) is an independent predictor of cardiovascular disease $\mathrm{s}^{4,5}$. Detecting microalbuminuria is an important screening tool to identify people who are at the risk of cardiovascular events \& who needs more intensive therapy compared with subjects having normal albumin excretion rates ${ }^{6}$. According to American Diabetic Association the gold standard for measuring urine microalbumin excretion is 24 hours urinary collection ${ }^{7}$ However, a more convenient method to detect microalbuminuria is urine albumin ( $\mathrm{mcg}$ ): creatinine $(\mathrm{mg})$ ratio (albumin creatinine ratio) measured in random sample ${ }^{6}$.
Currently the National Kidney foundation recommends the use of spot urine albumin creatinine ratio obtained under standardized conditions (first voided, morning, midstream sample) to detect microalbuminuria. Albumin creatinine ratio is acquired by this technique for our study.

Intima media thickness (IMT) is measurement of thickness of tunica media \& tunica intima, the innermost two layers of arterial wall. The measurement is usually made by external Doppler \& occasionally by internal,invasive ultrasound catheters. Carotid intima media thickness is strongly associated with atherosclerosis. Intimal thickening is a complex process; depending on a variety of factors including local hemodynamics, blood pressure etc. intima media thickness greater than $0.9 \mathrm{~mm}$ is almost certainly indicative of atherosclerosis \& increased risk of cardiovascular disease $^{6}$.The carotid artery is the usual site of measurement of intima media thickness\& the American Society of Echocardiography published a consensus statement on measurement of carotid intima media thickness in 2007

${ }^{8}$.Key advantages of external ultrasound method are

1) Low cost

2) Comfortable \& convenient for patient

3) Lack of invasive methods

4) Lack of radiation.

Intima media thickness \& albumin: creatinine ratio have been studied in past as markers of atherogenicity in various diseases like diabetes mellitus, smokers, renal failure, hypertension etc. However superiority of one technique over other in already established pathologies like proven ischaemic heart disease \& myocardial infarction have not been studied. Hence present study is undertaken. 


\section{International Journal of Science and Research (IJSR) \\ ISSN (Online): 2319-7064}

Index Copernicus Value (2013): 6.14 | Impact Factor (2014): 5.611

\section{Aims \& Objectives}

- To record \& analyse the presence of Micro albuminuria (Albumin: creatinine ratio $>30 \mathrm{ug} / \mathrm{mg}$ ) as a measure of atherogenicity in patient of ischaemic heart disease.

- To record \& analyse the presence of intima media thickening using carotid doppler study as a measure of atherogenicity in patients of ischaemic heart disease.

- To correlate the observed values of carotid intima media thickening with presence of albumin: creatinine ratio in studied subjects.

\section{Methods \& Material}

Type of study - Case control study

In present study 231 subjects were studied \& these were divided in following three groups

Case Group: Patients of ischaemic heart disease. $(n=106)$ Control Group I: Patients having hypertension, diabetes, alcoholism, obesity, dyslipidemia without evidence of ischaemic heart disease were considered as separate control group $(\mathrm{n}=50)$

Control Group II: Normal healthy individuals $(\mathrm{n}=75)$

Study Centre -

MGM medical college \& hospital, Aurangabad, Maharashtra, India.

\section{Inclusion Criteria}

1) Case group : Subjects of ischaemic heart disease of age more than 18 years of both gender as per $\mathrm{ECG}^{9}$, angiography ${ }^{10}$ findings of ischaemic heart disease with or without diabetes, smoking, dyslipidemia, obesity, alcoholism etc. were included

2) Control group I : Subjects of age more than 18 years of both gender having associated co morbidities but without evidence of ischaemic heart disease

3) Control group II: Normal individuals of age more than 18 years \& of both gender without evidence of ischaemic heart disease, diabetes mellitus, hypertension, dyslipidemia, alcoholism, smoking, obesity.

\section{Exclusion Criteria}

Patients of chronic renal failure were excluded from all 3 study groups.

\section{Statistical Analysis}

The collected data was compiled in MS excel sheet. For analysis of this data SPSS software (20th version) was used. The qualitative data was represented in form of frequency \& percentiles $\&$ also it was shown on bar diagram. To check association between different study groups (Case group, control group I, control group II) with different parameters/ attributes the Chi-square test was applied.

The sensitivity, specificity, negative predictive value, positive predictive value was calculated for different parameters like albumin creatinine ratio\&intima media thickness with Case group \& control group I and Case group $\&$ control group II. The p value was checked at 5\% level of significance.
All subjects were subjected to methods \& examinations with special attention to following parameters -

1) Age (years)

2) Weight $(\mathrm{kg})$

3) Height $(\mathrm{cm})$

4) BMI $(\mathrm{kg} / \mathrm{m} 2)$

5) $\mathrm{BP}(\mathrm{mm}-\mathrm{Hg})$

6) $\mathrm{ECG}$

7) Micro - albuminuria - Creatinine ratio by immunoturbidimetry

8) Carotid doppler study

9) Lipid profile

\section{Methodology}

Carotid scan was done by using B mode ultrasound of GE volution with a duplex colour Doppler machine\& an electric linear transducer having frequency of $13 \mathrm{MHz}$. A single specialist radiologist who had no idea about clinical data carried out all measurements. Scanning for carotid artery was done at 3 levels-

1) Common carotid artery $1 \mathrm{~cm}$ proximal to the bulb.

2) Internal carotid artery $1 \mathrm{~cm}$ distal to tip of the flow divider

3) Bifurcation bulb ( distance of $1 \mathrm{~cm}$ behind the tip of flow divider)

The intima media thickness was measured in $\mathrm{mm}$ as distance from leading echogenic line to second echogenic line.The first echogenic line represents the arterial lumen \& second represents the collagen containing upper layer of tunica adventitia. For each patient measurement of both sides were taken.

Sensitivity of intima media thickness is $65 \%$ \& specificity is $80 \%{ }^{11}$.

For the diagnosis of microalbuminuria, the morning, midstream sample was preferred. Patient was asked to refrain heavy exercises 24 hours prior to test. The morning, midstream sample was collected in sterile bulb.

Principles of the test -

- The microalbumin method (MALB) is based upon a particle enhanced turbidmetric inhibition immunoassay (PETINA) which allows direct quantification of albumin in urine sample.

- The MALB flex reagent cartridge contains a particulate reagent (PR) consisting of synthetic particles with human albumin bound to the surface.

- Aggregates of these particles are formed when a monoclonal antibody to human is introduced.

- Albumin present in the sample competes with the particles of the antibody thereby decreasing the rate of aggregation.

- Rate of aggregation is inversely proportional to the concentration of albumin in the sample.

- $\mathrm{PR}+\mathrm{Ab}+\mathrm{Alb}$ (sample) $-----\rightarrow \mathrm{PR}+\mathrm{Ab}+$ Alb (sample) Sensitivity of albumin creatinine ratio is $97 \%$ \& specificity is $92 \%{ }^{12}$ 


\section{International Journal of Science and Research (IJSR) ISSN (Online): 2319-7064 \\ Index Copernicus Value (2013): 6.14 | Impact Factor (2014): 5.611}

\section{Observation and Results}

This study was done in MGM Medical College, Aurangabad. The subjects were divided into three groups as follows.

Case Group: Patients of ischaemic heart disease. $(n=106)$

Control Group I: Patients having hypertension, diabetes, alcoholism, obesity, dyslipidemia without evidence of ischaemic heart disease were considered as separate control group $(\mathrm{n}=50)$

Control Group II: Normal healthy individuals $(\mathrm{n}=75)$

Statistical analysis was done and data was represented in the form of various tables and bar diagrams.

Table 1: Table showing Subjects according to gender

\begin{tabular}{|c|c|c|c|c|}
\hline Gender & Case Group & $\begin{array}{c}\text { Control } \\
\text { Group I }\end{array}$ & $\begin{array}{c}\text { Control } \\
\text { Group II }\end{array}$ & Total \\
\hline Male & $76(71.7 \%)$ & $20(40.0 \%)$ & $25(33.3 \%)$ & $121(52.4 \%)$ \\
\hline Female & $30(28.3 \%)$ & $30(60.0 \%)$ & $50(66.7 \%)$ & $110(47.6 \%)$ \\
\hline Total & $106(100 \%)$ & $50(100 \%)$ & $75(100 \%)$ & $231(100 \%)$ \\
\hline
\end{tabular}

Table 2: Table showing Subjects according to Age-Groups $\&$ mean age:

\begin{tabular}{|c|c|c|c|c|}
\hline Age-Group & $\begin{array}{c}\text { Case Group } \\
\mathrm{n}=106\end{array}$ & $\begin{array}{c}\text { Control } \\
\text { Group I } \\
\mathrm{n}=50\end{array}$ & $\begin{array}{c}\text { Control } \\
\text { Group II } \\
\mathrm{n}=75\end{array}$ & Total \\
\hline$<30$ & $02(1.88 \%)$ & $01(2 \%)$ & 00 & $03(1.2 \%)$ \\
\hline $31-40$ & $20(18.8 \%)$ & $10(20 \%)$ & $13(17.33 \%)$ & $43(18.61 \%)$ \\
\hline $41-50$ & $31(29.34 \%)$ & $16(32 \%)$ & $34(45.33 \%)$ & $81(35.06 \%)$ \\
\hline $51-60$ & $37(34.9 \%)$ & $12(24 \%)$ & $15(20 \%)$ & $64(27.7 \%)$ \\
\hline $61-70$ & $16(15.09 \%)$ & $09(18 \%)$ & $07(9.33 \%)$ & $33(14.28 \%)$ \\
\hline$>70$ & 00 & $02(4 \%)$ & $06(8 \%)$ & $08(3.46 \%)$ \\
\hline Total & $106(100 \%)$ & $50(100 \%)$ & $75(100 \%)$ & $231(100 \%)$ \\
\hline Mean \pm SD & $50.59 \pm 10.41$ & $50.36 \pm 11.72$ & $50.64 \pm 11.20$ & $50.55 \pm 10.93$ \\
\hline \multicolumn{5}{|c}{}
\end{tabular}

Table $1 \& 2$ show age $\&$ sex distribution of subjects in the study. Case group included predominantly males from 51 to 60 age group. Control group I \& II included predominantly females from 41 to 50 age group. The mean age of subjects from case group was $50.59 \pm 10.41$ years, mean age of subjects from control group I was $50.36 \pm 11.72$ years \& mean age of subjects from control group II was $50.64 \pm 11.20$ years. The overall mean age was $50.55 \pm 10.93$ years. The male: female ratio in Case group was 2.53 , in control group I was 0.66 , in control group II was $0.5 \&$ overall male: female ratio was 1.1

Table 3: Table showing Co-morbidities in 3 studied groups

\begin{tabular}{|c|c|c|c|c|c|c|}
\hline & & $\begin{array}{l}\text { Case Group } \\
\mathrm{n}=106\end{array}$ & $\begin{array}{l}\text { Control } \\
\text { Group I }\end{array}$ & Control Group II & $\begin{array}{l}\text { Chi-square } \\
\text { value }\end{array}$ & p-value \\
\hline \multirow{2}{*}{$\begin{array}{l}\text { Diabetes } \\
\text { mellitus } \\
\end{array}$} & Present & $01(0.94 \%)$ & $03(6 \%)$ & 00 & \multirow[t]{2}{*}{7.06} & $\mathrm{P}=0.026$ \\
\hline & Absent & $105(99.05 \%)$ & $47(94 \%)$ & 75 & & $\mathrm{~S}$ \\
\hline \multirow[t]{2}{*}{ Hypertension } & Present & $30(28.30 \%)$ & $28(56 \%)$ & 00 & \multirow[t]{2}{*}{51.1} & $\mathrm{P}=0.000$ \\
\hline & Absent & $76(71.69 \%)$ & $22(44 \%)$ & 75 & & $\mathrm{~S}$ \\
\hline
\end{tabular}

Table 3 shows distribution of Co morbidities present in the groups were diabetes mellitus\& hypertension, among which $1(0.9 \%)$ subject from case group, $3(6 \%)$ persons from control group I had diabetes mellitus. 30 (28.3\%) subjects from case group \& $28(56 \%)$ subjects from control group I had hypertension. This suggests that hypertension was the most prevalent co morbidity in this study. Both diabetes mellitus\& hypertension were found to be statistically significantly associated with different study groups.

Table 4: Table showing Family history of Co-morbidities in 3 studied groups:

\begin{tabular}{|c|c|c|c|c|c|c|}
\hline & & $\begin{array}{c}\text { Case Group } \\
n=106\end{array}$ & Control Group I & $\begin{array}{c}\text { Control Group } \\
\text { II } \\
\end{array}$ & $\begin{array}{c}\text { Chi-square } \\
\text { value }\end{array}$ & $P$-value \\
\hline \multirow{2}{*}{$\begin{array}{c}\text { Family History } \\
\text { Diabetes mellitus }\end{array}$} & Present & $46(43.3 \%)$ & $22(44 \%)$ & $21(28 \%)$ & \multirow[t]{2}{*}{21.89} & $\mathrm{P}=0.000$ \\
\hline & Absent & $60(56.7 \%)$ & $28(56 \%)$ & $54(72 \%)$ & & $\mathrm{S}$ \\
\hline \multirow{2}{*}{$\begin{array}{l}\text { Family History } \\
\text { Hypertension }\end{array}$} & Present & $25(23.5 \%)$ & $16(32 \%)$ & $08(10.66 \%)$ & \multirow[t]{2}{*}{8.83} & $\mathrm{P}=0.012$ \\
\hline & Absent & $81(76.5 \%)$ & $34(68 \%)$ & $67(89.34 \%)$ & & $\mathrm{S}$ \\
\hline
\end{tabular}

Table 4 shows the presence of family histories of diabetes mellitus\& hypertension in the subjects. 46 (43.3\%) subjects from case group had family history of diabetes mellitus\& 25 $(23.5 \%)$ had that of hypertension. $22(44 \%)$ subjects from control group I had family history of diabetes mellitus\& 16 $(32 \%)$ had that of hypertension. 21 (28\%) subjects from control group II had family history of diabetes mellitus\& 8 $(10.66 \%)$ that of hypertension. Family histories for both diabetes mellitus\& hypertension were statistically significant.

Table 5: Table showing Addictions in subjects in 3 studied groups

\begin{tabular}{|c|c|c|c|c|c|c|}
\hline \multicolumn{2}{|c|}{} & $\begin{array}{c}\text { Case Group } \\
n=106\end{array}$ & $\begin{array}{c}\text { Control Group } \\
I\end{array}$ & $\begin{array}{c}\text { Control } \\
\text { Group II }\end{array}$ & Chi-square value & P-value \\
\cline { 1 - 5 } $\begin{array}{c}\text { Addiction of } \\
\text { Smoking }\end{array}$ & YES & $48(45.28 \%)$ & $06(12 \%)$ & $04(5.33 \%)$ & 43.1 & $\mathrm{P}=0.000$ \\
\cline { 2 - 5 } & No & $58(54.72 \%)$ & $44(88 \%)$ & $71(94.67 \%)$ & & $\mathrm{S}$ \\
\hline $\begin{array}{c}\text { Addiction of } \\
\text { Alcohol }\end{array}$ & YES & $22(20.75 \%)$ & $2(4 \%)$ & $1(1.33 \%)$ & 20.2 & $\mathrm{P}=0.000$ \\
\cline { 2 - 5 } & No & $84(79.25 \%)$ & $48(96 \%)$ & $74(98.67 \%)$ & & $\mathrm{S}$ \\
\hline
\end{tabular}




\section{International Journal of Science and Research (IJSR) \\ ISSN (Online): 2319-7064 \\ Index Copernicus Value (2013): 6.14 | Impact Factor (2014): 5.611}

Table 5 shows prevalence of addictions in study subjects. 48 (45.28\%) subjects from case group had been found addicted to smoking \& $22(20.75 \%)$ were addicted to alcohol. 6 $(12 \%)$ subjects from control group I were addicted to smoking \& $2(4 \%)$ to that of alcohol. $4(5.33 \%)$ subjects from control group were addicted to smoking, whereas 1 $(1.33 \%)$ was alcoholic from control group II. Both addictions namely smoking \& alcoholism were statistically significant.

Table 6: Table showing distribution of Body Mass Index among 3 studied groups:

\begin{tabular}{|c|c|c|c|c|c|c|}
\hline \multicolumn{2}{|c|}{} & $\begin{array}{c}\text { Case Group } \\
\mathrm{n}=106\end{array}$ & $\begin{array}{c}\text { Control } \\
\text { Group I } \\
\mathrm{n}=50\end{array}$ & $\begin{array}{c}\text { Control } \\
\text { Group II } \\
\mathrm{n}=75\end{array}$ & Chi-square value & P-value \\
\hline \multirow{2}{*}{$\begin{array}{c}\text { Body } \\
\text { mass } \\
\text { index }\end{array}$} & Normal & $52(49.05 \%)$ & $21(42 \%)$ & $40(53.33 \%)$ & 4.53 & $\mathrm{P}=0.339$ \\
\cline { 2 - 5 } & Overweight & $46(43.39 \%)$ & $28(56 \%)$ & $32(42.66 \%)$ & & \\
\hline
\end{tabular}

Table 6 shows BMI of subjects from various study groups. $52(49.05 \%)$ subjects had normal BMI, 46 (43.39\%) are overweight \& $8(7.5 \%)$ were obese from case group. 21 $(42 \%)$ subjects had normal BMI, 28 (56\%) were overweight
\& 1(2\%) was obese from control group I. $40(53.33 \%)$ subjects from case group had normal BMI, $32(42.66 \%)$ were overweight \& 3 (4\%) were obese. The outcome of BMI was not significantly associated with study group.

Table 7: Table showing Lipid profile parameters in 3 studied groups:

\begin{tabular}{|c|c|c|c|c|c|c|}
\hline & & $\begin{array}{l}\text { Case Group } \\
\mathrm{n}=106\end{array}$ & $\begin{array}{l}\text { Control Group I } \\
\mathrm{n}=50\end{array}$ & $\begin{array}{l}\text { Control Group II } \\
\mathrm{n}=75\end{array}$ & $\begin{array}{l}\text { Chi-square } \\
\text { value }\end{array}$ & P-value \\
\hline \multirow[t]{2}{*}{ Cholesterol } & Normal & $93(87.73 \%)$ & $49(98 \%)$ & $68(90.66 \%)$ & \multirow[t]{2}{*}{4.34} & \multirow{2}{*}{$\begin{array}{l}\mathrm{P}=0.114 \\
\mathrm{NS}\end{array}$} \\
\hline & Abnormal & $13(12.26 \%)$ & $01(2 \%)$ & $07(9.34 \%)$ & & \\
\hline \multirow[t]{2}{*}{ Triglycerides } & Normal & $76(71.69 \%)$ & $38(76 \%)$ & $63(84 \%)$ & \multirow[t]{2}{*}{3.72} & $\mathrm{P}=0.155$ \\
\hline & Abnormal & $30(28.31 \%)$ & $12(24 \%)$ & $12(16 \%)$ & & NS \\
\hline \multirow{2}{*}{$\begin{array}{l}\text { High density } \\
\text { lipoprotein }\end{array}$} & Normal & $96(90.56 \%)$ & $47(94 \%)$ & $75(100 \%)$ & \multirow[t]{2}{*}{7.38} & $\mathrm{P}=0.025$ \\
\hline & Abnormal & $10(9.44 \%)$ & $03(6 \%)$ & 00 & & $\mathrm{~S}$ \\
\hline \multirow{2}{*}{$\begin{array}{l}\text { Low density } \\
\text { lipoprotein }\end{array}$} & Normal & $104(98.11 \%)$ & $49(98 \%)$ & $75(100 \%)$ & \multirow[t]{2}{*}{1.46} & $\mathrm{P}=0.146$ \\
\hline & Abnormal & $02(1.89 \%)$ & $1(2 \%)$ & 00 & & 0.481 \\
\hline
\end{tabular}

Table 7 shows parameters from lipid profile in various study groups. Among Parameters from lipid profile like cholesterol, HDL, LDL, triglycerides only the HDL was found to be statistically significant.10(9.44\%) from case group, 03(6\%) from control group I \& none from control group II had abnormal HDL values.13 (12.26\%) subjects from case group, $01(2 \%)$ subjects from control group I, 07
$(9.34 \%)$ subjects from control group II had raised cholesterol levels. 30 (28.31\%) subjects from case group, 12 (24\%) subjects from control group I, 12 (16\%) subjects from control group II had raised triglyceride levels. 02 (1.89\%) subjects from case group, $1(2 \%)$ subjects from control group I \& none from control group II had raised LDL levels.

Table 8: Table showing albumin creatinine ratio Outcome in 3 studied groups:

\begin{tabular}{|c|c|c|c|c|c|c|}
\hline & & $\begin{array}{c}\text { Case Group } \\
n=106\end{array}$ & $\begin{array}{c}\text { Control Group I } \\
\mathrm{n}=50\end{array}$ & $\begin{array}{c}\text { Control Group II } \\
\mathrm{n}=75\end{array}$ & Chi-square value & P-value \\
\hline Albumin & Positive & $62(58.49 \%)$ & $07(14 \%)$ & $04(5.33 \%)$ & 66.6 & $\mathrm{P}=0.000$ \\
\hline creatinine ratio & Negative & $44(41.59 \%)$ & $43(86 \%)$ & $71(94.67 \%)$ & & $\mathrm{S}$ \\
\hline
\end{tabular}

Table 8 shows albumin creatinine ratio outcome in various study groups. $62(58.49 \%)$ individuals from case group had positive albumin: creatinine ratio $(>30 \mathrm{mcg} / \mathrm{mg}), 7(14 \%)$ from control group I \& 4 (5.33\%) from control group II also had albumin creatinine ratio positive. This parameter was found to be statistically significant in current study.

Table 9: Table showing intima media thickness Outcome in 3 studied groups:

\begin{tabular}{|c|c|c|c|c|c|c|}
\hline \multicolumn{2}{|c|}{} & $\begin{array}{c}\text { Case Group } \\
\mathrm{n}=106\end{array}$ & $\begin{array}{c}\text { Control Group I } \\
\mathrm{n}=50\end{array}$ & $\begin{array}{c}\text { Control Group II } \\
\mathrm{n}=75\end{array}$ & $\begin{array}{c}\text { Chi-square } \\
\text { value }\end{array}$ & P-value \\
\hline $\begin{array}{c}\text { Intima Media } \\
\text { thickness }\end{array}$ & Positive & $36(33.96 \%)$ & $02(4 \%)$ & $05(6.66 \%)$ & 30.6 & $\mathrm{P}=0.000$ \\
\cline { 2 - 5 } & Negative & $70(66.04 \%)$ & $48(96 \%)$ & $70(93.34 \%)$ & & $\mathrm{S}$ \\
\hline
\end{tabular}

Table 9 shows intima media thickness outcome in various study groups 36 (33.96\%) individuals from case group had raised intima media thickness $(>0.9 \mathrm{~mm}), 2$ (4\%) from control group I \& 5 (6.66\%) from control group II also show raised intima media thickness. This parameter was found to be statistically significant in current study.
Sensitivity of albumin creatinine ratio among cases \& control group I was $89.86 \%$ \& specificity was $49.43 \%$ as per this study. Positive predictive value was $58.49 \%$ \& negative predictive value was $86 \%$. Sensitivity of albumin creatinine ratio among cases \& control group II was $93.94 \%$ \& specificity was $61.74 \%$ as per this study. 


\section{International Journal of Science and Research (IJSR) \\ ISSN (Online): 2319-7064 \\ Index Copernicus Value (2013): 6.14 | Impact Factor (2014): 5.611}

Positive predictive value was $58.49 \%$ \& negative predictive value was $94.47 \%$. Sensitivity of intima media thickness among cases \& control group I was $94.78 \%$ \& specificity was $40.68 \%$.Positive predictive value was33.96\% \& negative predictive value was $96 \%$. Sensitivity of intima media thickness among cases \& control group II was $87.80 \% \&$ specificity was $50 \%$.Positive predictive value was $33.96 \%$ \& negative predictive value was $93.33 \%$.

Intima media thickness had more sensitivity (94.78\%) \& negative predictive value (96\%); whereas albumin creatinine ratio had more specificity $(49.43 \%) \&$ positive predictive value $(58.49 \%)$. After comparative analysis of statistical parameters among case group \& control group II based on albumin creatinine ratio\&intima media thickness outcomes.Albumin creatinine ratio had more sensitivity (93.94\%), specificity $(61.74 \%)$, positive predictive value $(58.49 \%) \&$ negative predictive value $(94.47 \%)$.

\section{Discussion}

The present study was undertaken to evaluate the association between increased urinary albumin: creatinine ratio (ACR) \& carotid intima media thickness (IMT) as marker of atheroginicity in patients of ischaemic heart disease. Ischaemic heart disease was diagnosed on the basis of electrocardiogram (ECG).

Ischaemic heart disease is the most common cause of death in the world ${ }^{1}$. In India, ischaemic heart disease has become a leading cause of death, by 2004 accounting to 1.46 million deaths \& is expected to double by $2015^{2}$. Limitation of blood flow to the heart causes ischaemia (cell starvation secondary to a lack of oxygen) of the myocardial cells. Myocardial cells may die from lack of oxygen and this leads to ischaemic heart disease. There are certain predisposing factors like hypercholesterolemia, smoking, alcoholism, hypertension etc. Ischaemic heart disease may present as stable angina, unstable angina, acute coronary syndrome, myocardial infarction etc.

Microalbuminuria i.e albumin: creatinine ratio(ACR 30 to $300 \mathrm{mg} / \mathrm{lit}$ ) is an independent predictor of cardiovascular disease ${ }^{4,5}$. Detecting microalbuminuria is an important screening tool to identify people who are at the risk of cardiovascular events \& who needs more intensive therapy compared with subjects having normal albumin excretion rates $^{6}$. According to American Diabetic Association the gold standard for measuring urine microalbumin excretion is 24 hours urinary collection ${ }^{7}$. However, a more convenient method to detect microalbuminuria is urine albumin ( $\mathrm{mcg})$ : creatinine(mg) ratio (ACR) measured in random sample ${ }^{6}$. Currently the National Kidney foundation recommends the use of spot urine albumin creatinine ratio obtained under standardized conditions (first voided, morning, midstream sample) to detect microalbuminuria. Albumin creatinine ratio is acquired by this technique for our study.

Intima media thickness (IMT) is measurement of thickness of tunica media \& tunica intima, the innermost two layers of arterial wall. The measurement is usually made by external Doppler \& occasionally by internal, invasive ultrasound catheters. Carotid intima media thickness is strongly associated with atherosclerosis. Intimal thickening is a complex process; depending on a variety of factors including local hemodynamics, blood pressure etc. intima media thickness greater than $0.9 \mathrm{~mm}$ is almost certainly indicative of atherosclerosis \& increased risk of cardiovascular disease $^{6}$. The carotid artery is the usual site of measurement of intima media thickness\& the American Society of Echocardiography published a consensus statement on measurement of carotid intima media thickness in $2007^{8}$.

The current study investigated the prevalence of microalbuminuria (ACR) and carotid intima media thickness $\&$ the association with Smoking, Hypertension, Abnormal lipid profile, BMI, and Diabetes in subjects of ischaemic heart disease, subjects with comorbidities but without ischaemic heart disease (control group I) \& normal individuals (control group II).

\section{Albumin creatinine ratio in the Study Group}

Out of the 106 subjects in the study, the prevalence of microalbuminuria was in $58 \%$ of studied subjects show in table no. 9. 14\% from control group I \& 5.33\% from control group II also had albumin creatinine ratio positive. The prevalence was higher in case group in relation to control group I \& control group II. The prevalence in the present study is relatively similar to number of studies. The iSEARCH global study 2007 also reported the overall prevalence of microalbuminuria in more than 20,000 individuals from 26 countries as $58 \%{ }^{9}$ this high prevalence could be due to several factors. Microalbuminuria was detected on single occasion using urine sample in both studies. The other factor that might lead to the increased prevalence of microalbuminuria reported in the i-SEARCH study and our study is that the population studied had complex comorbidities diabetes, hypertension, dyslipidemia.

\section{Albumin creatinine ratio and Diabetes}

The current study had $0.9 \%$ diabetic out of 106 subjects\& $6 \%$ are diabetic from control group I, Microalbuminuria was found in $50 \%$ of patients with diabetes in our study. Diabetic subjects in Case group with Microalbuminuria are 100\% and in control group I are $33 \%$ as seen in table no 4 which is statistically significant. This prevalence was more in our study than in HOPE and Micro- HOPE studies of 2000, only $33 \%$ diabetics had microalbuminuria ${ }^{10}$. The prevalence in patients with diabetes $(n=10,640)$ in the Advance study 2009, was $27 \%{ }^{11}$. The Advance and HOPE studies, the selection criteria of patients enrolled involved the presence of cardiovascular disease in addition to diabetes mellitus, hence the prevalence of microalbuminuria tends to be high in these patients, similar observation was seen in the present study ${ }^{12}$. The low percentage of patients with 4 diabetes in the current study undoubtedly affects the microalbuminuria prevalence. In the I-DEMAND study $2010(n=3534), 37 \%$ of the participants in the cohort had diabetes mellitus compared with $2.5 \%$ in my study.

\section{Albumin creatinine ratio and ischaemic heart disease}

The prevalence of raised albumin creatinine ratio in studied subjects is $31.6 \%$.The prevalence of microalbuminuria in significant ischaemic heart disease subjects is higher $58.49 \%$ in comparison to control groups $8 \%$. This difference observed in table no. 9 is statistically significant .Several 


\section{International Journal of Science and Research (IJSR) \\ ISSN (Online): 2319-7064}

Index Copernicus Value (2013): 6.14 | Impact Factor (2014): 5.611

epidemiological studies like Life 2003, The Cardiovascular Health 2006, Aloft 2011 suggested similar significant association between microalbuminuria (positive albumin creatinine ratio) and cardiovascular diseases. ${ }^{13,14,15}$

\section{Albumin creatinine ratio and Hypertension:}

In this study $25.1 \%$ of subjects were hypertensive. The prevalence in case group was $28.3 \%$ and $56 \%$ in control group I as seen in table no. 4. Microalbuminuria was seen in $73 \%$ of subjects with hypertension and $53.57 \%$ of control group I hypertensive patients which is statistically significant. Microalbuminuria was strongly associated with hypertension in Case group, a finding that agrees with most reported studies on hypertensive subjects. ${ }^{16,17,18}$ A causal relationship is supported by the observation of Secret 2009, and Road Map 2012 that strict control of blood pressure prevents the development of microalbuminuria and that blood pressure control reduces albuminuria. ${ }^{19,20}$

\begin{abstract}
Albumin creatinine ratio and Dyslipidemia:
Dyslipidemia was defined as cholesterol value $>200 \mathrm{mg} / \mathrm{dl}^{21}$ or triglyceride value $>150 \mathrm{mg} / \mathrm{dl}$ or subjects on anti-lipid drugs $^{22}$. In this study $32.46 \%$ of subjects were having dyslipidemia. The prevalence in case group is $44.33 \%$ and $26 \%$ from control group I \& $25.33 \%$ from control group II. Microalbuminuria was seen in $72.09 \%$ of case group dyslipidemia subjects and $38.46 \%$ of control group I dyslipidemia subjects \& $31.57 \%$ of control group II which is statistically as seen in table No. 8. There is a significant association in the dyslipidemia and microalbuminuric individuals in case group in present study. The study are similar with those reported in several epidemiological studies like Gubbio Population Study 1998 where the prevalence of dyslipidemia was frequent in subjects with microalbuminuria. ${ }^{23,24,25}$
\end{abstract}

\section{Albumin creatinine ratio and Smoking:}

In the present study there are $25.1 \%$ smokers, case group had $45.28 \%$, control group I had $12 \%$ \& control group II had $5.33 \%$ smokers. Microalbuminuria in case group smokers is $26.41 \%$ and $16.66 \%$ in control group I \& none from control group II shown in table no 6 , significant association is seen in microalbuminuria and smoking in both groups. This finding is consistent with findings that reported in iSEARCH 2010 a positive association between cigarette smoking and the prevalence of microalbuminuria. ${ }^{26,27}$

\section{Albumin creatinine ratio and Alcohol: \\ In our study no significant association was seen in microalbuminuria and alcohol in both groups (A and B). The prevalence is $10.82 \%$ in study, but only $20.24 \%$ in case group, $4 \%$ from control group I and $1.33 \%$ in control group II .The sample size is too small for any correlation.}

Intima- media thickening and ischaemic heart disease: Out of the 106 subjects in the study, the prevalence of raised intima media thickness was in $33.96 \%$ of studied subjects show in table no. 9. $4 \%$ from control group I \& $6.66 \%$ from control group II also had intima media thickness positive. The similar observations were found in other studies. ${ }^{28,29}$ The studies carried by Howard NH et al \& Petra C.G.Simmons et al are suggestive of definite relationship between increased intima media thickness\& ischaemic heart disease.

\section{Intima- media thickening and diabetes mellitus:}

The study had $0.9 \%$ diabetic out of 106 subjects \& $6 \%$ are diabetic from control group I. 23 studies including 24111 subjects, 4019 with diabetes showed that intima media thickness was greater in diabetics than control group ${ }^{30}$.

\section{Intima- media thickening and hypertension:}

In this study $25.1 \%$ of subjects were hypertensive. The prevalence in case group was $28.3 \%$ and $56 \%$ in control group I as seen in table no. 4 . $23.5 \%$ from case group \& $44 \%$ from control group I hypertensives had raised intima media thickness. Prevalence of carotid artery wall alterations among the hypertensive subjects randomly allocated to treatment in the ELSA trial was very high: $82 \%$ had $T_{\max }>$ $1.3 \mathrm{~mm}$ (_plaques' according to protocol) and $17 \%$ had $T_{\max }$ $>1.0$ and $<1.3 \mathrm{~mm}$ (thickening ${ }^{\circ}$ ). Analysis of baseline data from the ELSA has shown that there is an extremely marked prevalence of carotid artery wall alterations among mild-tomoderate, middle-aged hypertensive patients ${ }^{31}$.

\section{Intima- media thickening and dyslipidemia:}

In this study $32.46 \%$ of subjects were having dyslipidemia. The prevalence in case group is $44.33 \%$ and $26 \%$ from control group I \& $25.33 \%$ from control group II. Raised intima media thickness is seen in $46.66 \%$ of case group and $23.52 \%$ of control group I dyslipidemia subjects\& $10.52 \%$ of control group II which is statistically as seen in table No. 8. The combination of FRS with Max-intima media thickness measurement can be used in routine clinical practice to greatly enhance the predictability of cardiovascular events in the large number of patients who fall into the intermediate-risk category, which currently does not call for aggressive preventive measures.In Kaplan-Meier analysis, the Max-intima media thickness significantly improved the predictive value of the Framingham risk score $^{32}$.

\section{Conclusion and Summary}

Both albumin creatinine ratio \& intima media thickness were found to be highly significant after analysis of all the study groups $(p=0.000)$. Sensitivity of albumin creatinine ratio among subjects\& control group I is $89.86 \%$ \& specificity is $49.43 \%$ as per this study. Positive predictive value is $58.49 \%$ $\&$ negative predictive value is $86 \%$.Sensitivity of albumin creatinine ratio among cases \& control group II is $93.94 \%$ \& specificity is $61.74 \%$ as per this study. Positive predictive value is $58.49 \%$ \& negative predictive value is $94.47 \%$.Sensitivity of intima media thickness among cases \& control group I is $94.78 \%$ \& specificity is $40.68 \%$. Positive predictive value is $33.96 \%$ \& negative predictive value is $96 \%$.Sensitivity of intima media thickness among cases \& control group II is $87.80 \%$ \& specificity is $50 \%$. Positive predictive value is $33.96 \%$ \& negative predictive value is $93.33 \%$.The association between intima media thickness and albumin creatinine ratio outcome in ischaemic heart disease is found statistically significant $(\mathrm{p}<0.05)$.

Other factors like age, sex, diabetes mellitus, hypertension, addiction to smoking \& alcohol, family history of diabetes mellitus\& hypertension were also found to have significant 


\section{International Journal of Science and Research (IJSR) \\ ISSN (Online): 2319-7064}

Index Copernicus Value (2013): 6.14 | Impact Factor (2014): 5.611

association $(\mathrm{p}<0.05)$ with albumin creatinine ratio \& intima media thickness outcomes.

Intima media thickness is more sensitive marker of atheroginicity among case group \& control group I \&albumin creatinine ratio is more sensitive marker of atheroginicity among case group \& control group II suggesting that albumin creatinine ratio outcome has more correlation with comorbidities that exist with ischaemic heart disease like diabetes mellitus\& hypertension which themselves can cause albumin excretion by causing nephropathy. Intima media thickness has direct association more with the progress of atherogenesis when comorbidities exist.

\section{References}

[1] Finegold, JA; Asaria, P et al," .Mortality from ischaemic heart disease by country, region, and age: Statistics from World Health Organisation and United Nations.”, International journal of cardiology, 168 (2), pp. 934-45, 2012.

[2] Gupta R, Joshi et al." Epidemiology and causation of coronary heart disease and stroke in India", Heart, 94 (1), pp.16-26, 2008.

[3] Kristian Thygesen, Joseph S Alpert, Allan S Jaffe, Maarten L Simoons, Bernard R Chaitman and Harvey D White," the Writing Group on behalf of the Joint ESC/ACCF/AHA/WHF Task Force for the Universal Definition of Myocardial Infarction” ,J Am CollCardiol.,60(16), pp.1581-1598,2012.

[4] Rossing P, Hougaard P, Borch-Johnsen K, Parving H," Predictors of mortality in insulin dependent diabetes, 10-year observational follow up study”, ,Br Med J, 313,pp. 779-784,1996.

[5] Ljungman S, Wikstrand J, Hartford M, Berglund G et al." Urinary albumin excretion: A predictor of risk of cardiovascular disease-A prospective 10-year followup of middle aged nondiabetic normal and hypertensive men", Am J Hypertens, , 9, pp. 770-778,1996.

[6] Keane WF, Eknoyan G," Proteinuria, albuminuria, risk, assessment, detection, elimination (PARADE): A position paper of the National Kidney Foundation", Am J Kidney Dis, 9, pp. 1004-1010, 1999.

[7] Pignoli P," Ultrasound B-mode imaging for arterial wall thickness measurement", Atherosclerosis Reviews. , 12, pp. 177-184, 1984.

[8] James H Stein, Claudia E Korcarz, R. Todd Hurst, Eva Lonn,Christopher B. Kendall, Emile R Mohler, Samer S Najjar,Christopher M Rembold and Wendy S Postet al.” Use of Carotid Ultrasound to Identify Subclinical Vascular Disease and Evaluate Cardiovascular Disease Risk, A Consensus Statement from the American Society of Echocardiography Carotid Intima-Media Thickness Task Force Endorsed by the Society for Vascular Medicine"Journal of the American Society of Echocardiography, 21(2), pp. 93-111, 2008.

[9] V. Puddu, R. Bernard et al." Nomenclature and criteria for diagnosis of ischemic heart disease. Report of the Joint International Society and Federation of Cardiology/World Health Organization task force on standardization of clinical nomenclature", Circulation, 1979(59),pp.607-609,2014.
[10]John A. Ambrose et al." Angiographic evolution of coronary artery morphology in unstable angina", Journal of American society of cardiology, 7(3), pp. 472-478, 1986.

[11]A Kablak Ziembicka, W Tracz, T Przewlocki et al. Association of increased carotid intima-media thickness with the extent of coronary artery disease", Heart,90(11), pp. 1286-1290, 2004.

[12]P.T Sawicki, L Heinemann, M Berger et al." Albumin creatinine ratio as marker of microalbuminuria", Diabetes UK, pp. 1464-67, 2009.

[13] Bohm M, Thoenes M, Danchin N et al. Association of cardiovascular risk factors with microalbuminuria in hypertensive individuals: the i-SEARCH global study", J Hypertens, , 25, pp. 2317-24,2002.

[14]Heart Outcomes Prevention Evaluation Study Investigators Effects of ramipril on cardiovascular and microvascular outcomes in people with diabetes mellitus: results of the HOPE study and MICRO-HOPE substudy. Heart Outcomes Prevention Evaluation Study Investigators", Lancet, 355, pp. 253-59, 2000.

[15] Ninomiya T, Perkovic V, de Galan B, et al. Albuminuria and kidney function independently predict cardiovascular and renal outcomes in diabetes", J Am Soc Nephrol, 20, pp. 1813, 2009.

[16] Mlacak B, Jaksic Z, Vuletic S et al." Albuminuria, cardiovascular morbidity and mortality in diabetic and non-diabetic subjects in a rural general practice", Fam Pract, 16, pp. 580-85,1999.

[17] Wachtell K, Ibsen H, Olser M et al." Albuminuria and cardiovascular risk in hypertensive patients with left ventricular hypertrophy: the LIFE Study", Ann Intern Med, 139, pp. 901-06, 2003.

[18] Cao J, Barzilay J, Peterson D et al. The association of microalbuminuria with clinical cardiovascular disease and subclinical atherosclerosis in the elderly: The Cardiovascular Health Study", Atherosclerosis, 187, pp. 372-77, 2006.

[19] Jackson C, MacDonald M, Petrie M et al." The Aliskiren Observation of heart Failure Treatment investigators. Associations of albuminuria in patients with chronic heart failure: findings in the Aliskiren Observation of heart Failure Treatment study", Eur J Heart Fail, 13, pp. 746-54, 2011.

[20] Moran A, Palmas W, Pickering T," Office and ambulatory blood pressure are independently associated with albuminuria in older subjects with type 2 diabetes", Hypertension, 47, pp. 955-61, 2006.

[21] Lurbe, E, Redon, J, Kesani, A, Pascual et al. Increase in nocturnal blood pressure and progression to microalbuminuria in type 1 diabetes", N Engl J Med, 347, pp. 797-805, 2007.

[22] Dell'omo, G, Giorgi, D, Di Bello, V et al." Blood pressure independent association of microalbuminuria and left ventricular hypertrophy in hypertensive men", J Intern Med, 254, pp. 76-84, 2005.

[23] Philipp T, Martinez F, Geiger H, et al." Candesartan improves blood pressure control and reduces proteinuria in renal transplant recipients: results from SECRET", Nephrol Dial Transplant, 25, pp. 967-76, 2009.

[24] Menne J, Izzo J, Ito $S$ et al. Prevention of microalbuminuria in patients with type 2 diabetes and hypertension”, J Hypertens, 30, pp. 811-18, 2012. 
[25] Cooper A, O‘Flynn N. Risk assessment and lipid modification for primary and secondary prevention of cardiovascular disease: summary of NICE guidance", BMJ, 336, pp. 1246-48, 2008.

[26] Manninen V, Tenkanen L, Koskinen P, et al. Joint effects of serum triglyceride and LDL cholesterol and HDL cholesterol concentrations on coronary heart disease risk in the Helsinki Heart Study. Implications for treatment", Circulation, 85, pp. 37-45, 1992.

[27]Cirillo M, Senigalliesi L, Laurenzi $M$ et al. Microalbuminuria in nondiabetic adults: relation of blood pressure, body mass index, plasma cholesterol levels, and smoking: the Gubbio Population Study", Arch Intern Med, 158, pp. 1933-39, 1998.

[28] Howard N Hodis, Wendy J Mack, Laurie LaBree et al. The Role of Carotid Arterial Intima-Media Thickness in Predicting Clinical Coronary Events",Ann Intern Med., 128(4), pp. 262-269, 1998.

[29] Petra CG Simons, Ale Algra, Michiel L Bots et al."Common Carotid Intima-Media Thickness and Arterial Stiffness Indicators of Cardiovascular Risk in High-Risk Patients The SMART Study", Circulation, 100, pp. 951-957, 1999.

[30] Campese V, Bianchi S, Bigazzi R. Association between hyperlipidemia and microalbuminuria in essential hypertension", Kidney Int, 56, p. S10-S13, 1999

[31] Salles G, Cardoso C, Fiszman R, Muxfeldt E." Prognostic importance of baseline and serial changes in microalbuminuria in patients with resistant hypertension", Atherosclerosis, 216, pp. 199-204, 2011.

[32] Ukena C, Mahfoud F, Kindermann M et al." Smoking is associated with a high prevalence of microalbuminuria in hypertensive high-risk patients: data from ISEARCH", Clinical Research in Cardiology , 99, pp. 825-32, 2010.

[33] Pinto-Sietsma S, Mulder J, Janssen J et al. Smoking is related to albuminuria and abnormal renal function in nondiabetic persons", Ann Intern Med, 133, pp. 585-91, 2000.

[34] G. Brohall et al. -Garotid artery intima- media thickness in patients with type 2 diabetes mellitus and impaired glucose tolerence: A systematic review", Diabetic medicine, 23(6), pp. 609-16, 2006.

[35]Zanchetti, Albetro et al. Risk factors associated with alterations in carotid intima-media thickness in hypertension: Baseline data from the European lacidipine study on atherosclerosis", Journal of hypertension, 16(7), pp. 949-961, 1998.

[36]Damiano Baldassarre et al. - Measurement of carotid artery intima-media thickness in dyslipidemic patients increases the power of traditional risk factors to predict cardiovascular events", Atherosclerosis, 191(2), pp. 403-408, 2007. 